\title{
Association of Hyperuricemia With Immune Disorders and Intestinal Barrier Dysfunction
}

\author{
Qiulan Lv't, Daxing Xu1t, Xuezhi Zhang't, Xiaomin Yang ${ }^{1}$, Peng Zhao ${ }^{1}$, Xuena Cui ${ }^{1}$, \\ Xiu Liu', Wan Yang ${ }^{1}$, Guanpin Yang ${ }^{2}$ and Shichao Xing ${ }^{1,3,4 *}$ \\ 'Medical Research Center, Affiliated Hospital of Qingdao University, Qingdao, China, ${ }^{2}$ The Key Laboratory of Mariculture, \\ Ministry of Education, Ocean University of China, Qingdao, China, ${ }^{3}$ Institute of Sports Medicine and Health, Qingdao \\ University, Qingdao, China, ${ }^{4}$ Guy's \& St Thomas' Hospital, King's College London, London, United Kingdom
}

\section{OPEN ACCESS}

Edited by:

Stephen J. Pandol,

Cedars-Sinai Medical Center.

United States

Reviewed by:

Markov Georgievich Alexandr Saint Petersburg State University,

Russia

Sunil Yeruva,

Ludwig Maximilian University of Munich, Germany

*Correspondence:

Shichao Xing

xingshichao@qdu.edu.cn orcid.org/0000-0001-7704-2813

${ }^{\dagger}$ These authors have contributed equally to this work

Specialty section:

This article was submitted to

Gastrointestinal Sciences, a section of the journal

Frontiers in Physiology

Received: 03 January 2020 Accepted: 20 October 2020 Published: 27 November 2020

Citation

$L v Q, X u D$, Zhang $X$, Yang $X$, Zhao $P$, Cui $X$, Liu $X$, Yang $W$, Yang $G$ and Xing $S$ (2020) Association of Hyperuricemia With Immune Disorders and Intestinal Barrier Dysfunction

Front. Physiol. 11:524236. doi: 10.3389/fphys.2020.524236
Background: More than $30-40 \%$ of uric acid is excreted via the intestine, and the dysfunction of intestinal epithelium disrupts uric acid excretion. The involvement of gut microbiota in hyperuricemia has been reported in previous studies, but the changes and mechanisms of intestinal immunity in hyperuricemia are still unknown.

Methods: This study developed a urate oxidase (Uox)-knockout (Uox-/-) mouse model for hyperuricemia using CRISPR/Cas9 technology. The lipometabolism was assessed by measuring changes in biochemical indicators. Furthermore, 4-kDa fluorescein isothiocyanate-labeled dextran was used to assess gut barrier function. Also, 16S rRNA sequencing was performed to examine the changes in gut microbiota in mouse feces. RNA sequencing, Western blot, Q-PCR, ELISA, and immunohistochemical analysis were used for measuring gene transcription, the number of immune cells, and the levels of cytokines in intestinal tissues, serum, kidney, liver, pancreas, and vascellum.

Results: This study showed that the abundance of inflammation-related microbiota increased in hyperuricemic mice. The microbial pattern recognition-associated Tolllike receptor pathway and inflammation-associated TNF and NF-kappa B signaling pathways were significantly enriched. The increased abundance of inflammationrelated microbiota resulted in immune disorders and intestinal barrier dysfunction by upregulating TLR2/4/5 and promoting the release of IL-1 $\beta$ and TNF- $\alpha$. The levels of epithelial tight junction proteins occludin and claudin-1 decreased. The expression of the pro-apoptotic gene Bax increased. The levels of LPS and TNF- $\alpha$ in systemic circulation increased in hyperuricemic mice. A positive correlation was observed between the increase in intestinal permeability and serum levels of uric acid.

Conclusion: Hyperuricemia was characterized by dysregulated intestinal immunity, compromised intestinal barrier, and systemic inflammation. These findings might serve as a basis for future novel therapeutic interventions for hyperuricemia.

Keywords: hyperuricemia, gut microbiota, intestinal immune, intestinal barrier, system inflammation 


\section{INTRODUCTION}

Hyperuricemia is a systemic disease caused by purine metabolic disorder. It is often a result of gout and renal disease, and accompanied by metabolic syndrome (Johnson et al., 2013; Debosch et al., 2014; Abeles, 2015). Lu et al. (2018) showed that hyperuricemia was associated with metabolic disorders in a urate oxidase (Uox)-knockout mouse model. Both clinical and basic studies supported the hypothesis that hyperuricemia was an independent risk factor for hypertension and cardiovascular diseases. The prevalence of hypertension, obesity, and hypertriglyceridemia in hyperuricemia is 69.1, 62.9, and $53.7 \%$, respectively (Bardin and Richette, 2017). Hyperuricemia has become increasingly common worldwide with changes in diet and lifestyle. The prevalence of hyperuricemia has reached $21.4 \%$ in the United States and $13.3 \%$ in mainland China. Numerous anti-hyperuricemia drugs targeted at kidneys have been developed; monotherapy seriously exerts adverse effects on renal function. Hence, diverse and innovative strategies against hyperuricemia are urgently needed.

The gut is one of the largest endocrine organs, harboring thousands of microbial communities in the body. The dysbiosis of gut microbiota and immunity is associated with numerous metabolic diseases. Recent studies on the pathogenic mechanisms of hyperuricemia focus on the gut. More than $30-40 \%$ of uric acid is excreted by the intestine, and defects in intestinal clearance result in hyperuricemia (Atsushi et al., 2012; Hosomi et al., 2012). It has been established that gut microbiota participate in the metabolism of purine and uric acid (Crane, 2013; John et al., 2013). Studies have also shown that gut microbiota was considerably altered in patients with gout (Crane, 2013; Guo et al., 2016; Shao et al., 2017). These findings suggest that the gut could be a promising new therapeutic target for hyperuricemia. However, whether gut microbiota have biological effects on hyperuricemia is still unknown. Microbiota dysbiosis has a major effect on mucosal immunity, resulting in increased intestinal permeability. A weakened intestinal barrier allows the leakage of gut bacteria, inflammatory cytokines, and bacterial products such as LPS across the barrier and into the systemic circulation, which further interacts with multiple organs to cause systemic inflammation and worsen the situation (Winer et al., 2016). However, whether the changes in the microbiota in mouse models of hyperuricemia could result in alterations in intestinal immunity remains unclear. Thus, a better understanding of changes in intestinal immunity in hyperuricemia is urgently needed.

\section{MATERIALS AND METHODS}

\section{Animals and Models}

All experiments involving mice were carried out in accordance with the protocols approved by the Animal Research Ethics Committee of the Affiliated Hospital of Qingdao University. This study established a Uox-knockout (Uox-/-) mouse model for hyperuricemia using CRISPR/Cas9 technology on C57BL/6J background. Six homozygous mice (Uox-/-) and six wild-type mice (WT) were used for experiments. The mice were housed in sterile and ventilated cages at $23^{\circ} \mathrm{C}$ and under a $12-\mathrm{h}$ light-dark cycle. Throughout the study, the mice received a standard chow diet and water. Blood samples were collected by retro-orbital bleeding after fasting overnight. The levels of biochemical indicators, including serum uric acid, triglyceride (TC), total cholesterol (TG), and high- and low-density lipoprotein cholesterol (HDL and LDL), were determined using an automatic biochemical analyzer (Toshiba, Tokyo, Japan). Fecal samples were collected between 8 and 9 AM. The mice were weighed every week and sacrificed at an age of 15 weeks (six mice for each group). The kidney, liver, vascellum, pancreas, jejunum, ileum, and colon were sampled. Under basal conditions, mice with a weight loss of $15 \%$ under basal conditions were excluded from the study.

\section{$16 S$ rRNA Gene Sequencing and Gut Microbiota Analysis}

Frozen fecal samples were processed for DNA isolation, and the variable region V1-V3 of $16 \mathrm{~S}$ rRNA was amplified using the primers 27F ( $5^{\prime}$-AGA GTT TGA TCC TGG CTC AG-3') and 533R (5'-TTA CCG CGG CTG CTG GCA C$\left.3^{\prime}\right)$. PCR was performed by denaturing at $98^{\circ} \mathrm{C}$ for $30 \mathrm{~s}$, followed by 25 cycles of denaturation at $98^{\circ} \mathrm{C}$ for $10 \mathrm{~s}$, annealing at $55^{\circ} \mathrm{C}$ for $30 \mathrm{~s}$, extension at $72^{\circ} \mathrm{C}$ for $30 \mathrm{~s}$, and a final extension at $72^{\circ} \mathrm{C}$ for $5 \mathrm{~min}$. The product was subsequently pooled and purified (standard gel extraction kits, Qiagen) and by Beijing Biomarker technology. Sequence data were screened and filtered for quality, and the taxonomical classification was performed using the Ribosomal Database Project (RDP)-classifier against the Greengenes reference database (Ye, 2011; Stearns et al., 2015). Sequences sharing $97 \%$ nucleotide sequence identity were clustered into operational taxonomic units (97\% ID OTUs). NMDS plot for testing beta-diversity was generated in QIIME. The linear discriminant analysis effect size (LEfSe) was used for detecting discrepant bacteria among groups, and bar plots were made in $R^{1}$. Raw sequencing data of the $V 1-V 3$ region of the $16 \mathrm{~S}$ rRNA gene and the accompanying information were available in the Sequence Read Archive database under accession number: PRJNA600173.

\section{RNA Isolation and RNA Sequencing}

Total RNA was isolated using TRIzol reagent (Life Technologies, United States). The mRNA was captured with Dynabeads oligo (dT) (Life Technologies). The samples were sequenced using the BGISEQ-500 platform, and about $24.08 \mathrm{M}$ reads per sample were generated. Clean reads were mapped to the reference genome using HISAT $^{2}$. The clean reads were mapped to reference transcripts using Bowtie $2^{3}$, and then the gene expression level was calculated for each sample with RSEM ${ }^{4}$. KEGG pathway classification and functional enrichment were performed.

\footnotetext{
${ }^{1}$ http://www.R-project.org/

${ }^{2}$ http://www.ccb.jhu.edu/software/hisat

${ }^{3}$ http://bowtie-bio.sourceforge.net/Bowtie2/index.shtml

${ }^{4}$ http://deweylab.biostat.wisc.edu/RSEM
} 


\section{Western Blot Analysis}

Tissues were cut into small pieces and homogenized in radioimmunoprecipitation assay (RIPA) buffer containing 1\% PMSF on ice. The supernatant was collected after centrifugation at $14,000 \mathrm{rpm}$ for $15 \mathrm{~min}$. Then, $90 \mu \mathrm{g}$ protein was loaded onto 15 or $10 \%$ sodium dodecyl sulfate-polyacrylamide gel electrophoresis and transferred onto polyvinylidene fluoride membranes (Millipore, MA, United States). The membranes were blocked for $2 \mathrm{~h}$ at room temperature with $5 \%$ skimmed milk and then incubated with the following primary antibodies: mouse anti-TLR4 (Cat\# sc-293072, RRID:AB_10611320, 1:500, Santa Cruz Biotechnology, United States), mouse anti-TLR5 (Cat\# NB100-80842, RRID:AB_2205149 1:500, Novus, United States), rabbit anti-TLR2 (ab213676, 1:200, Abcam, United States), rabbit anti-IL-1 $\beta$ (Cat\# ab9722, RRID:AB_308765, 1:1000, Abcam), rabbit anti-TNF- $\alpha$ (Cat\# ab6671, RRID:AB_305641, 1:500, Abcam), mouse anti-occludin (Cat\# 33-1500, RRID:AB_2533101, 1:1500, Thermo Fisher Scientific, United States), and rabbit anti-claudin-1 (Cat\# NBP1-77036, RRID:AB_11026235, 1:1000, Novus) overnight at $4^{\circ} \mathrm{C}$. The membranes were washed with TBST three times and incubated with anti-mouse IgG and horseradish peroxidase (HRP)-conjugated secondary antibodies (Cat\# 7076, RRID:AB_330924, 1:6000, CST, United States) or anti-rabbit IgG and HRP-linked antibody (Cat\# 7074, RRID:AB_2099233, 1:6000, CST, United States) at room temperature (RT) for $1 \mathrm{~h}$. The protein signals were detected on an imaging system using a chemiluminescence kit (Millipore, MA, United States) and analyzed using Image-Pro Plus software (Bio-Rad, United States). Image-Pro Plus software was used to perform the gray-scale of Western Blot for the semiquantitative. Protein expression normalized to that of $\beta$-actin.

\section{RNA Extraction and Real-Time Quantitative PCR}

Total RNAs from the kidney, liver, pancreas, vascellum, ileum, jejunum, and colon were extracted using TRIzol reagent (Life Technologies, United States) following the manufacturer's protocols. The cDNA was synthesized using a PrimeScript RT reagent kit (Takara, Tokyo, Japan) following the manufacturer's instructions. Real-time PCR was performed in triplicate on an ABI 7500 Fast System using SDS software with an SYBR Premix Ex Taq kit (Takara, Kyoto, Japan). The specific primers were designed using Primer 5 software and synthesized by Sangon Biotech (Table 1). All primers were verified for the production of a single specific PCR product with a melting curve program. The fold increase in mRNA abundance was calculated by the $2^{-\Delta \Delta C t}$ method and normalized to GAPDH as an internal control.

\section{Hematoxylin-Eosin and Immunohistochemical Analyses}

Histopathological analysis was carried out using hematoxylineosin (H\&E) on samples from the ileum, jejunum, and colon of WT and Uox ${ }^{-/-}$mice. The tissues were formalin-inflated and then paraffin-embedded. The paraffin-embedded tissue blocks
TABLE 1 | The sequences of the primers.

\begin{tabular}{|c|c|c|c|}
\hline Names & Primers & Sequence & Species \\
\hline \multirow[t]{2}{*}{ NOD1 } & Forward $\left(5^{\prime} \rightarrow 3^{\prime}\right)$ & CGGCAGCGGAAGTGGAAGAAG & Mice \\
\hline & Reverse $\left(5^{\prime} \rightarrow 3^{\prime}\right)$ & GTGTTGACTCAGTCTCGCTTCCTC & \\
\hline \multirow[t]{2}{*}{ NOD2 } & Forward $\left(5^{\prime} \rightarrow 3^{\prime}\right)$ & GTGTTGACTCAGTCTCGCTTCCTC & Mice \\
\hline & Reverse $\left(5^{\prime} \rightarrow 3^{\prime}\right)$ & GTGTCGGCATCTCTGTTCAGGTG & \\
\hline \multirow[t]{2}{*}{ TLR4 } & Forward $\left(5^{\prime} \rightarrow 3^{\prime}\right)$ & GCAGAAAATGCCAGGATGATG & Mice \\
\hline & Reverse $\left(5^{\prime} \rightarrow 3^{\prime}\right)$ & AACTACCTCTATGCAGGGATTCAAG & \\
\hline \multirow[t]{2}{*}{ TLR2 } & Forward $\left(5^{\prime} \rightarrow 3^{\prime}\right)$ & СTCCСACTTCAGGCTCTITG & Mice \\
\hline & Reverse $\left(5^{\prime} \rightarrow 3^{\prime}\right)$ & AGGAACTGGGTGGAGAACCT & \\
\hline \multirow[t]{2}{*}{ TLR3 } & Forward $\left(5^{\prime} \rightarrow 3^{\prime}\right)$ & CAGGCGTCCTTGGACTTGAAGC & Mice \\
\hline & Reverse $\left(5^{\prime} \rightarrow 3^{\prime}\right)$ & TGCTGAACTGCGTGATGTACCTTG & \\
\hline \multirow[t]{2}{*}{ TLR5 } & Forward $\left(5^{\prime} \rightarrow 3^{\prime}\right)$ & CCACCGAAGACTGCGATGAAGAG & Mice \\
\hline & Reverse $\left(5^{\prime} \rightarrow 3^{\prime}\right)$ & CCAGACCTTGTCCTTGAACACCAG & \\
\hline \multirow[t]{2}{*}{ TLR7 } & Forward $\left(5^{\prime} \rightarrow 3^{\prime}\right)$ & ATCGTGGACTGCACAGACAAGC & Mice \\
\hline & Reverse $\left(5^{\prime} \rightarrow 3^{\prime}\right)$ & AGCCTACGGAAGGAATCTGGAGAG & \\
\hline \multirow[t]{2}{*}{ TLR9 } & Forward $\left(5^{\prime} \rightarrow 3^{\prime}\right)$ & GACTTCAGCGGCAACGGTATGG & Mice \\
\hline & Reverse $\left(5^{\prime} \rightarrow 3^{\prime}\right)$ & TAGTTGTCTCGGAGGCTCAGCAG & \\
\hline \multirow[t]{2}{*}{ NLRP3 } & Forward $\left(5^{\prime} \rightarrow 3^{\prime}\right)$ & ATGCTGCTTCGACATCTCCT & Mice \\
\hline & Reverse $\left(5^{\prime} \rightarrow 3^{\prime}\right)$ & AACCAATGCGAGATCCTGAC & \\
\hline \multirow[t]{2}{*}{ Occludin } & Forward $\left(5^{\prime} \rightarrow 3^{\prime}\right)$ & TTGAAAGTCCACCTCCTTACAGA & Mice \\
\hline & Reverse $\left(5^{\prime} \rightarrow 3^{\prime}\right)$ & CCGGATAAAAAGAGTACGCTGG & \\
\hline \multirow[t]{2}{*}{$\mathrm{ZO}-1$} & Forward $\left(5^{\prime} \rightarrow 3^{\prime}\right)$ & АСТСССАСТТССССАААААС & Mice \\
\hline & Reverse $\left(5^{\prime} \rightarrow 3^{\prime}\right)$ & CCACAGCTGAAGGACTCACA & \\
\hline \multirow[t]{2}{*}{ Bak1 } & Forward $\left(5^{\prime} \rightarrow 3^{\prime}\right)$ & GGTCTITCGAAGCTACGTIIT & Mice \\
\hline & Reverse $\left(5^{\prime} \rightarrow 3^{\prime}\right)$ & ATCTTGGTGAAGAGTTCGTAGG & \\
\hline \multirow[t]{2}{*}{ Bax } & Forward $\left(5^{\prime} \rightarrow 3^{\prime}\right)$ & CCATGATGGTTCTGATCAGCTC & Mice \\
\hline & Reverse $\left(5^{\prime} \rightarrow 3^{\prime}\right)$ & TTGCССTCTTCTACTITGCTAG & \\
\hline \multirow[t]{2}{*}{$\mathrm{Bcl} 2 \mathrm{l} 10$} & Forward $\left(5^{\prime} \rightarrow 3^{\prime}\right)$ & TGACTACATATTCTTCTGCGC & Mice \\
\hline & Reverse $\left(5^{\prime} \rightarrow 3^{\prime}\right)$ & CTITGGAGAGCAACTTATCTGC & \\
\hline \multirow[t]{3}{*}{ GAPDH } & Forward $\left(5^{\prime} \rightarrow 3^{\prime}\right)$ & AAATGGTGAAGGTCGGTGTGAACG & Mice \\
\hline & Reverse $\left(5^{\prime} \rightarrow 3^{\prime}\right)$ & ATCTCCACTITGCCACTGC & \\
\hline & Reverse $\left(5^{\prime} \rightarrow 3^{\prime}\right)$ & ACA TTG GGG GTA GGA ACA CGG A & \\
\hline
\end{tabular}

were stained with $\mathrm{H} \& \mathrm{E}$, and epithelial architecture was scored and mounted on an optical microscope (Olympus, Japan).

For immunohistochemical analysis, the tissue was blocked with $5 \%$ goat serum, containing $0.25 \%$ Triton- 100 for $1 \mathrm{~h}$ at RT and incubated with primary antibodies against CD68 (1:200, Santa Cruz Biotechnology), CD3 (1:200, Abcam), and claudin1 (1:200, Santa Cruz Biotechnology) at $4^{\circ} \mathrm{C}$ overnight. The tissue that was not incubated with specific primary antibodies was used as a negative control. The slices were incubated with specific secondary antibodies (1:1000, CST) for $1 \mathrm{~h}$ at RT after washing with PBS three times. Images were then obtained with an Olympus Provis AX70 microscope (Olympus, Japan).

\section{Measuring the Permeability of the Epithelial Barrier Using FITC-Labeled Dextran}

The 4-kDa fluorescein isothiocyanate (FITC)-labeled dextran (FD4; Sigma-Aldrich) was used to assess in vivo intestinal permeability. The mice were deprived of water for $4 \mathrm{~h}$ prior to an oral gavage (40 mg/100 g body weight) with FITC-labeled dextran at a concentration of $80 \mathrm{mg} / \mathrm{mL}$ in PBS. After $4 \mathrm{~h}$, 
blood was collected by retro-orbital bleeding and centrifuged at $2000 \mathrm{rpm}$ for $10 \mathrm{~min}$. The serum was collected, and fluorescence intensity was measured on fluorescence plates using an excitation wavelength of $485 \mathrm{~nm}$ and an emission wavelength of $528 \mathrm{~nm}$.

\section{Measurement of the Serum Levels of LPS, IL-1 $\beta$, and TNF- $\alpha$}

Serum levels of LPS, IL- $1 \beta$, and TNF- $\alpha$ were measured using an ELISA kit (Mibio, China) in duplicate $(n=6)$ following the manufacturer's instructions. Briefly, plates with specific antibodies were incubated with serum or tissue homogenates, washed, and incubated with HRP-avidin before quantification. The absorbance at $405 \mathrm{~nm}$ was measured with a microplate reader. The total proteins in the kidney, liver, pancreas, and vascellum were detected using a BCA Protein Assay kit (Thermo, United States). The contents of IL-1 $\beta$ and TNF- $\alpha$ in tissues were normalized to total protein.

\section{Statistical Analysis}

All data were displayed as the mean \pm standard error of the mean (SEM). Hyperuricemia and control groups were compared using the Student unpaired-sample $t$-test, and comparisons of more than three groups were analyzed by analysis of variance with Tukey's post hoc test using SPSS 17.0. $P$-values $<0.05$ indicated statistically significant differences.

\section{RESULTS}

\section{Lipometabolism Was Disordered in Hyperuricemic Mice}

This study used a mouse model featuring Uox genetic dysfunction, leading to hyperuricemia. Significant differences were detected in the serum levels of uric acid between the two groups (Figure 1A). The serum levels of TC and LDL increased in hyperuricemic mice, suggesting a risk of hyperuricemia for patients with cardiovascular disease and stroke (Figures 1B,C). An increase in the HDL level was observed (Figure 1D), indicating disorders of lipid metabolism. However, no changes in triglyceride and blood glucose levels were found between hyperuricemic and WT mice (Figures 1E,F). The morphology of the kidney in hyperuricemic mice was significantly abnormal, including collapsed and necrotic nephrons, interstitial edema, and inflammatory cell infiltration (blue dot-shaped cells marked

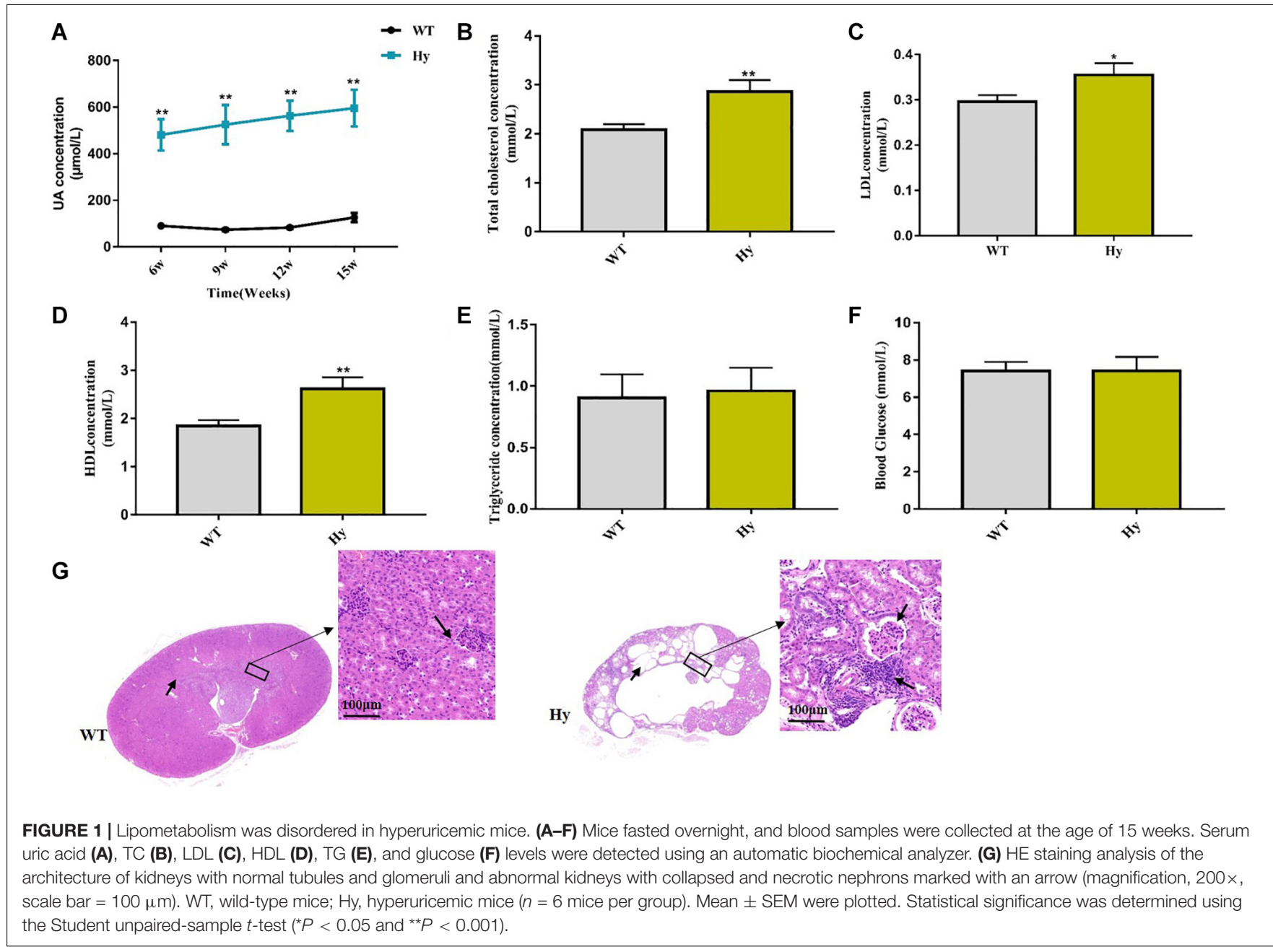


A

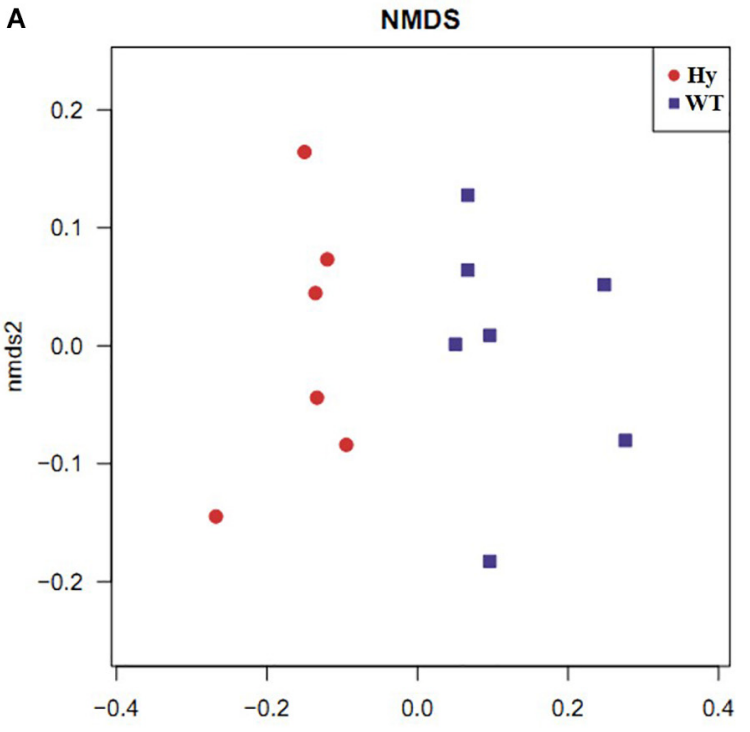

C

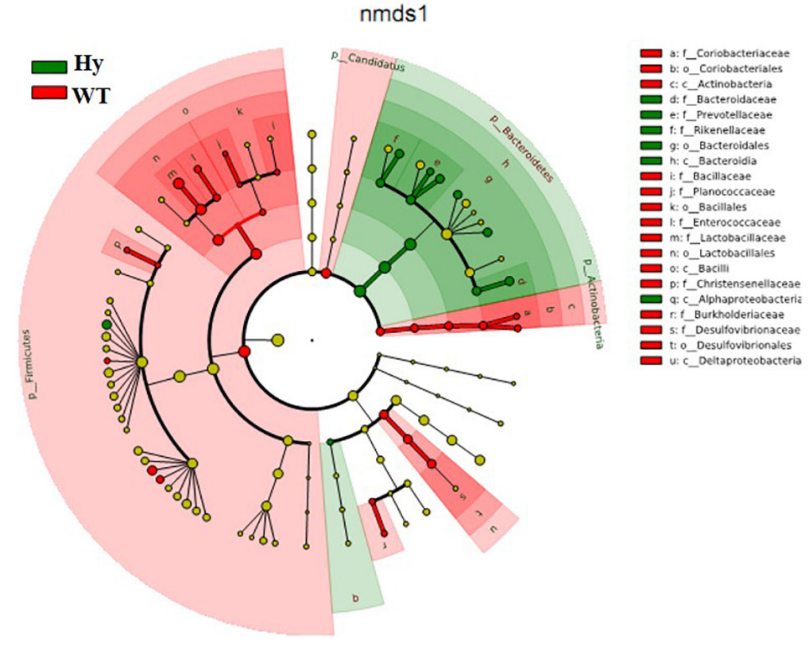

B
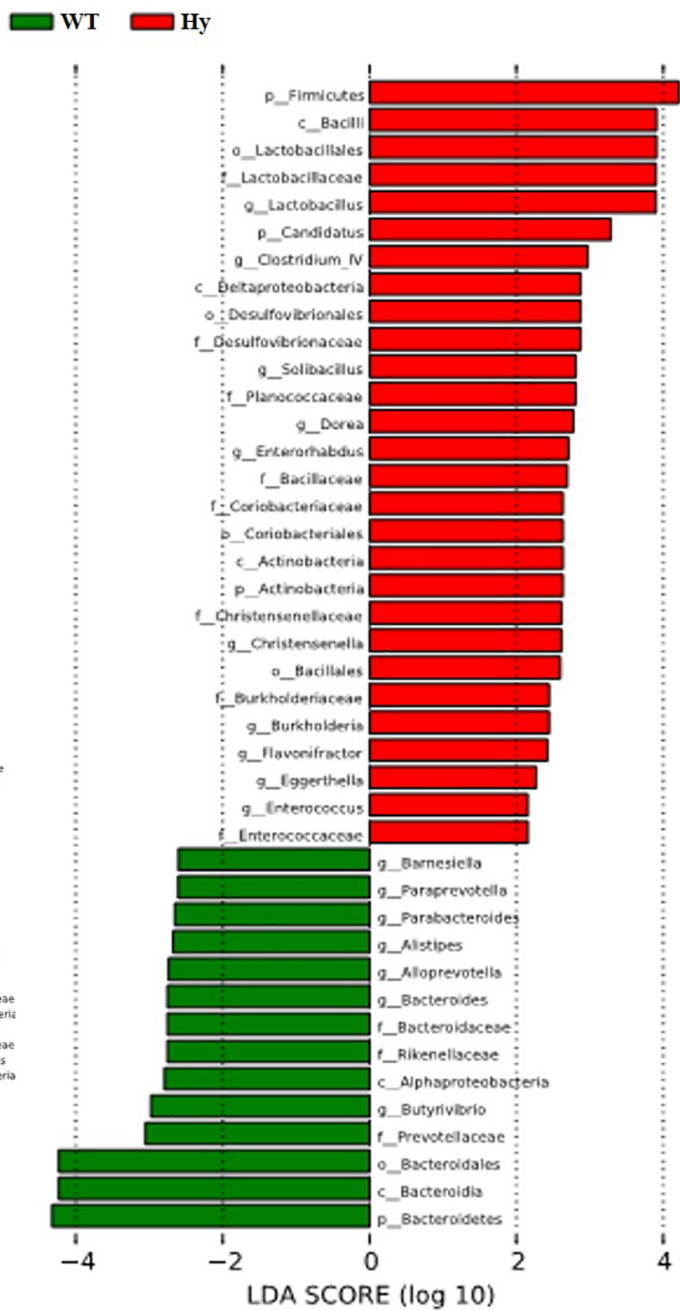

FIGURE 2 | Microbial dysbiosis occurred in hyperuricemic mice. The taxa summary of microbiota was achieved using the Ribosomal Database Project (RDP)-classifier. Sequences sharing 97\% nucleotide sequence identity were clustered into operational taxonomic units (97\% ID OTUs). (A) The community composition was analyzed using NMDS based on unweighted UniFrac distance; (B,C) The microbiota composition was analyzed using LEfSe ( $n=7)$. WT, wild-type mice; Hy, hyperuricemic mice.

with an arrow). We also noted lamellar necrosis of epithelial cells in renal tubules (Figure 1G).

\section{Microbiota Composition Was Altered in Hyperuricemic Mice}

Preclinical animal models of hyperuricemic mice featuring Uox genetic dysfunction were used to investigate the causative link between altered microbiota and gut pathology. As showed by the results of this study, Hyperuricemic mice had microbiota dysbiosis. NMDS based on unweighted UniFrac distance showed two separate clusters with highly distinct community composition (Figure 2A). The discrepant bacterial taxa between the two groups were further analyzed using LEfSe analysis. As shown in Figures $\mathbf{2 B}, \mathbf{C}$, the abundance of Bacteroides, Alloprevotella, and intestinal inflammation-associated bacteria, such as Alistipes and Parabacteroides, significantly increased in hyperuricemic mice, while the major butyrate-producing genera, such as Clostridium, and protective bacterium Lactobacillus, and anaerobic bacteria such as Candidatus and members of Coriobacteriaceae, were depleted.

Finally, the correlation between the uric acid level and bacterial abundance was analyzed using Pearson correlation coefficients with $P<0.05$ to preliminarily verify the association between microbiota and hyperuricemia. Five (Alloprevotella, Alistipes, Butyrivibrio, Bacteroides, and Barnesiella) and three (Clostridium_XlVa, Burkholderia, and Christensenella) bacterial genera having a positive and negative correlation with uric acid, respectively, were identified in the present study (Table 2). The bacteria having a positive correlation with uric acid were also associated with intestinal inflammation. These results 
TABLE 2 | The correlation between bacteria and UA content in mouse.

\begin{tabular}{lcc}
\hline Gut bacteria & \multicolumn{2}{c}{ Mouse } \\
\cline { 2 - 3 } & $\boldsymbol{R}$ value & Significance level \\
\hline Christensenellaceae & -0.62 & $*$ \\
Coriobacteriaceae & -0.7 & $*$ \\
Bacteroidaceae & 0.6 & $*$ \\
Rikenellaceae & 0.68 & $*$ \\
Prevotellaceae & 0.62 & $*$ \\
Planococcaceae & -0.78 & $*$ \\
Desulfovibrionaceae & -0.72 & $*$ \\
Lactobacillaceae & -0.74 & $*$ \\
Streptococcaceae & -0.64 & $*$ \\
Burkholderiaceae & -0.61 & $*$ \\
Enterococcaceae & -0.61 & $*$ \\
Bacteroides & 0.6 & $*$ \\
Alloprevotella & 0.74 & $*$ \\
Alistipes & 0.74 & $*$ \\
Butyrivibrio & 0.64 & $*$ \\
Barnesiella & 0.56 & $*$ \\
Clostridium_XIVa & -0.67 & $*$ \\
Burkholderia & -0.61 & $*$ \\
Christensenella & -0.62 & $*$ \\
\hline Asterisks, & $*$ \\
& $*$ \\
& $*$ \\
\hline
\end{tabular}

Asterisks, the significance of discrepancy, ${ }^{*} P<0.01,{ }^{*} P<0.05$.

demonstrated that the altered microbiota was a signature of gut inflammation.

\section{Gut Microbiota Disturbed Intestinal Immunity}

The abundance of inflammation-associated bacteria increased in hyperuricemic mice, especially in the intestine. RNA sequencing was performed to compare intestinal mRNA levels between WT and hyperuricemic mice to investigate the mechanisms by which gut microbiota affected intestinal epithelial function. Pathway functional enrichment was explored through KEGG pathway enrichment to highlight the DEGs relevant to bacterial infectious diseases between WT and hyperuricemic mice. As shown in Figures $3 \mathbf{A}, \mathbf{B}$, microbial pattern recognition associated with the Toll-like receptor pathway and inflammation-associated TNF and NF-kappa B signaling pathways were enriched. Furthermore, several DEGs associated with bacterial infectious diseases, such as Staphylococcus aureus, Salmonella, and pathogenic Escherichia coli, were also enriched. Moreover, inflammatory bowel diseaseand bacterial invasion-associated DEGs were also significantly enriched. The findings were confirmed using Q-PCR. We evaluated changes in the levels of microbial pattern recognition receptors in the ileum, jejunum, and colonic tissue. As shown in Figures 3C-E, the genes whose expression most strongly upregulated in hyperuricemic mice were TLR2, TLR4, and TLR5, which are indicative of gut dysbiosis. The expression of TLR2, TLR4, TLR5, and NLRP3 was significantly aberrant, especially in the jejunum. However, the protein level of TLR4 remained unchanged in the ileum, jejunum, and colon. The level of only TLR2 protein increased in the jejunum, and the level of
TLR5 protein increased in the colon (Figures 3F-H). The levels of pro-inflammatory cytokines were further determined using Western blot analysis. As shown in Figures 3I,J, the augmented expression of TNF- $\alpha$ was observed in the ileum, jejunum, and colon. Furthermore, the level of inflammatory bowel diseaseassociated factor IL-1 $\beta$ was also elevated in the ileum, jejunum, and colon. These data indicated that the altered microbiota composition in hyperuricemia was accompanied by changes in intestinal immunity.

\section{Hyperuricemia Was Characterized by Compromised Intestinal Barrier and Infiltration of Lymphocytic Cells}

The association of intestinal inflammation and epithelial barrier dysfunction with hyperuricemia was further examined. The concentration of serum FD4 was detected after 6, 9, 12, and 15 weeks. As shown in Figure $\mathbf{4 A}$, a feature common to hyperuricemic mice at different time points was a compromised barrier. Notably, older mice had higher intestinal permeability in both hyperuricemia and WT groups. The intestinal permeability increased with age in both hyperuricemia and WT mice. However, the increase was robust in the hyperuricemia group, but slight in the WT group. It seemed that age might predispose hyperuricemic mice to the exacerbation of intestinal barrier dysfunction. A positive correlation was observed between increased intestinal permeability and uric acid levels $(r=0.79$, $P<0.01)$, indicating that increased intestinal permeability might contribute to hyperuricemia (Figure 4B). Together, these observations indicated that hyperuricemia was characterized by a compromised intestinal barrier. The epithelial structure was stained with $\mathrm{H} \& \mathrm{E}$ to further examine pathological changes in the intestinal mucosa. However, no gross differences were found in the intestinal architecture of the ileum, jejunum, and colon (Figure 4C). This study further examined inflammatory cell infiltration in the intestine. As shown in Figures 4D,E, significant lymphocytic $\left(\mathrm{CD}^{+}\right)$infiltration was found in the ileum, jejunum, and colon in the hyperuricemic mice compared with the WT mice, revealing the infiltration of lymphocytic cells into the intestinal epithelium.

\section{Molecular Mechanisms That Involved in a Compromised Intestinal Barrier}

The expression of epithelial tight junction proteins was assessed to further investigate the molecular mechanisms involved in a compromised intestinal barrier. We measured the mRNA expression of occludin and ZO-1. As shown in Figures $\mathbf{5 A - C}$, the expression of the occludin gene was lower only in the jejunum, while ZO-1 mRNA levels were unaffected. However, the protein expression of occludin was markedly attenuated in the ileum and jejunum but slightly changed in the colon. The expression of tight junction proteins occludin and claudin-1 were also lower in the jejunum and colon (Figures 5D,E). The present study further analyzed the expression of pro- and anti-apoptotic genes. As shown in Figures 5F-H, the expression of the pro-apoptotic gene Bax significantly increased in both the ileum and jejunum, 
A

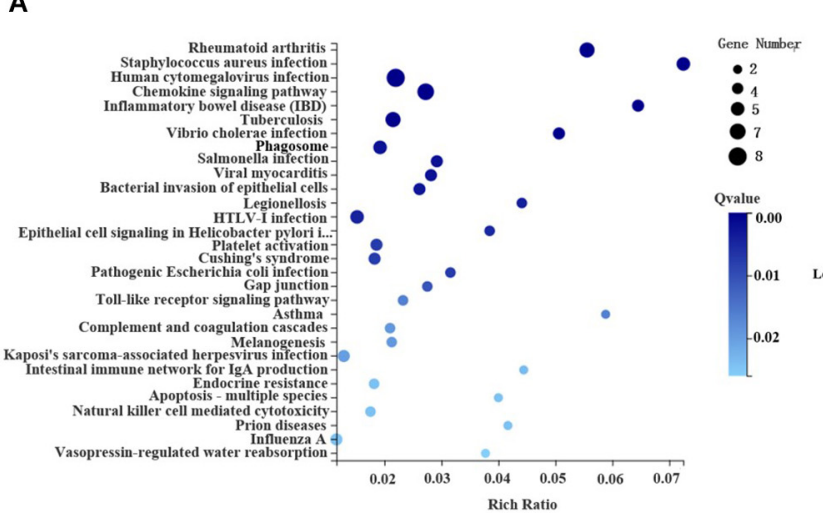

C

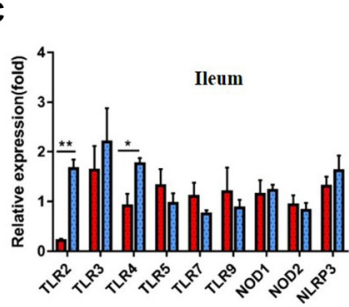

B

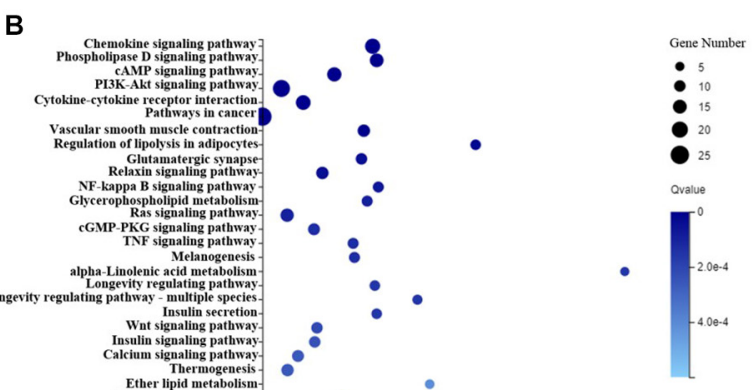

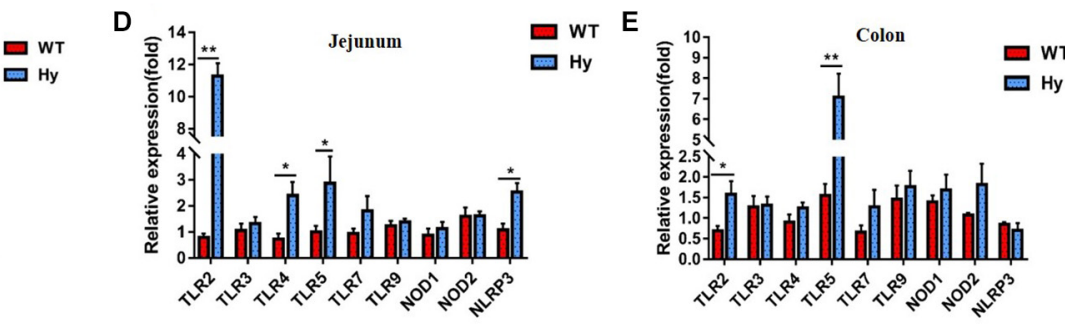
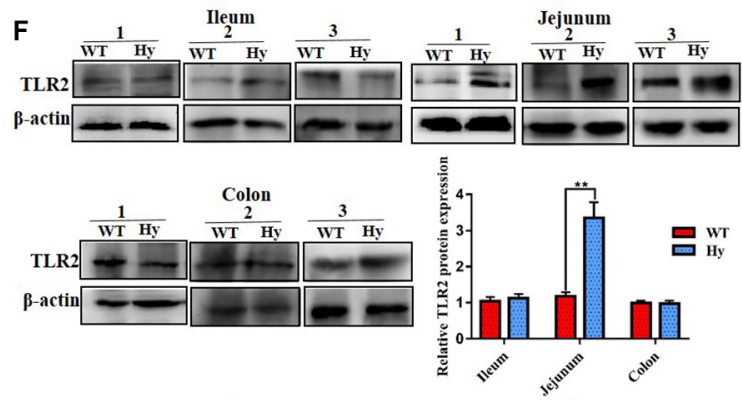

H

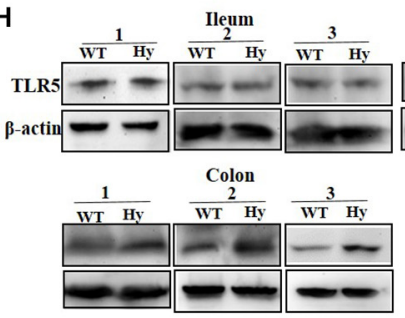

$\frac{1}{\text { WT }}$

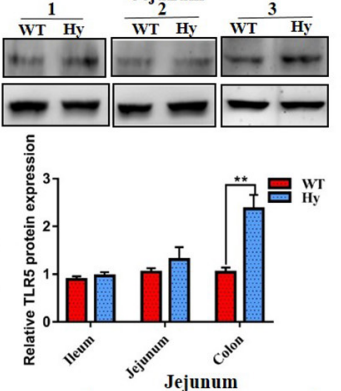

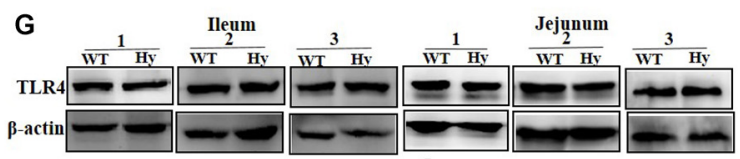

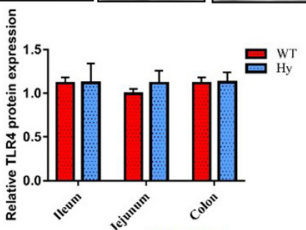

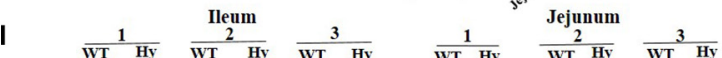
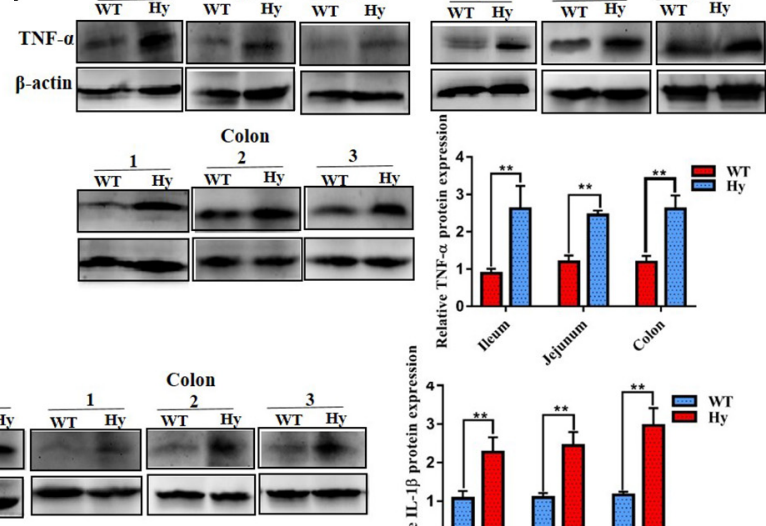

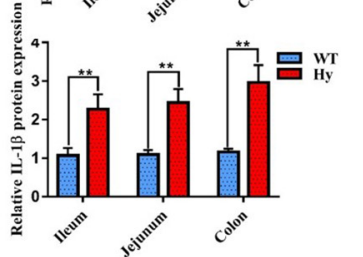

FIGURE 3 | Hyperuricemic mice had increased intestinal inflammation. (A,B) The most pathway functional enrichment of DEGs is associated with bacterial infectious diseases and signal transduction pathways. The $x$-axis represents the enrichment factor. The $y$-axis represents the pathway name. The color indicates the $q$-value (high: white; low: blue), and the lower $q$-value indicates more significant enrichment. Point size indicates the DEG number (the bigger dots refer to a larger amount). Rich factor refers to the value of enrichment factor, which is the quotient of the foreground value (the number of DEGs) and the background value (total gene amount). The larger the value, the more significant the enrichment. (C-E) Gene expression of TLRs and NLRs in the ileum (B,C), jejunum (D), and colon (E) was determined using Q-PCR ( $n=6$ mice per group). (F-H) Protein density of TLR2 (F), TLR4 (G), and TLR5 (H) from the ileum, jejunum, and colon tissue was determined using Western blot analysis. (I,J) Expression of TNF- $\alpha \mathbf{( I )}$ and IL-1 $\beta$ (J) in the ileum, jejunum, and colon was verified by Western blot analysis. Data represent three independent experiments. Mean \pm SEM were plotted. Statistical significance was determined using the Student unpaired-sample $t$-test $\left({ }^{\star} P<0.05\right.$ and $\left.{ }^{\star \star} P<0.001\right)$. 

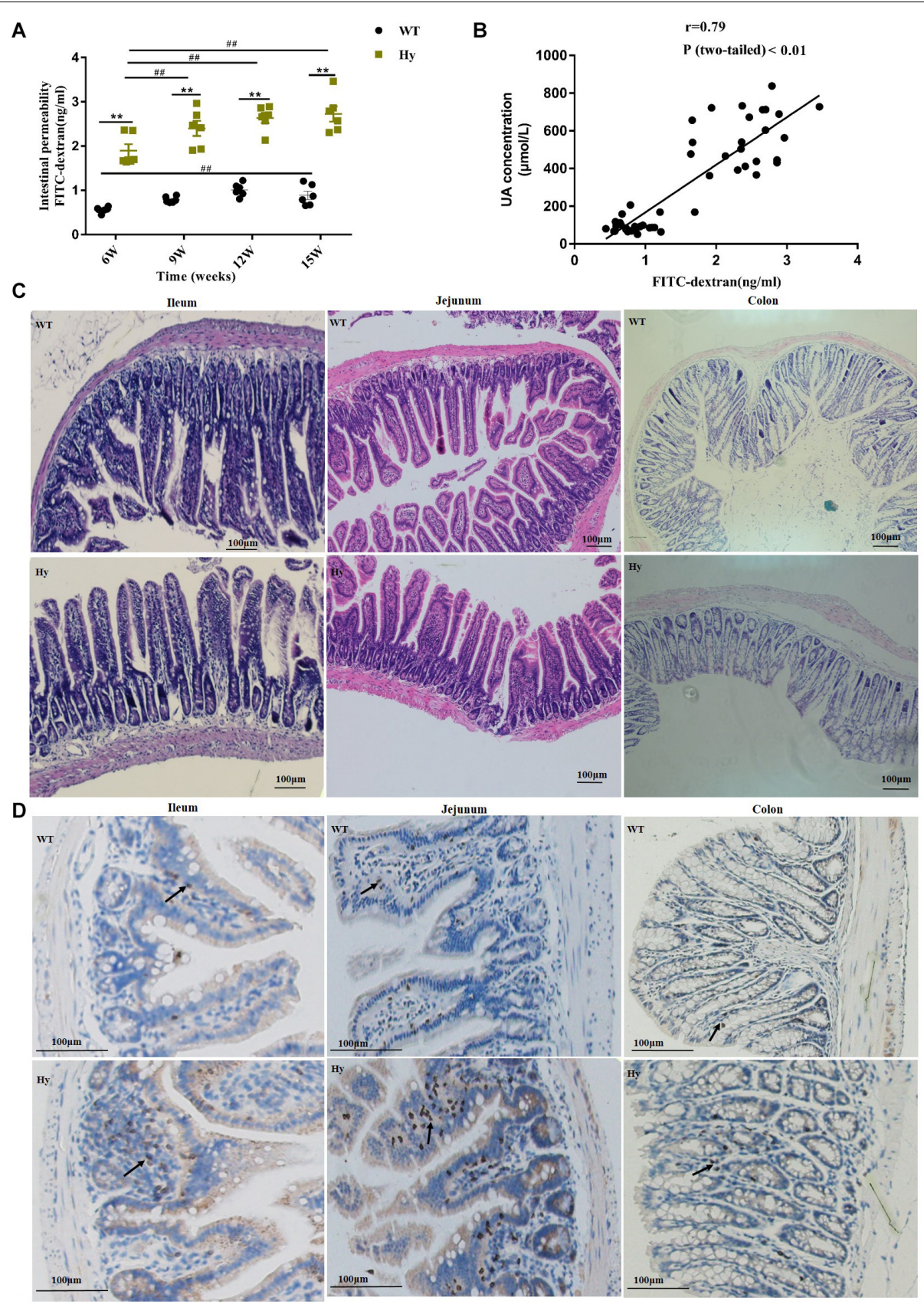

E

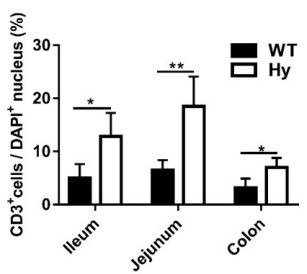

FIGURE 4 | Hyperuricemia was associated with intestinal barrier dysfunction. (A) Intestinal permeability was measured in WT and Hy mice at the age of 6, 9, 12, and 15 weeks by oral gavage with FD4, and fluorescence translocation into the plasma were determined. (B) Correlation of intestinal permeability with the uric acid level was analyzed using Pearson correlation coefficients with $P<0.05$. (C) Epithelial architecture of the ileum, jejunum, and colon, analyzed by staining with H\&E (100x magnification). (D) Representative image of immunohistochemical staining for CD3+ (brown) in the ileum, jejunum, and colon. Arrows indicate positive cells. All photos were taken at $100 \times$, scare bar $=100 \mu \mathrm{m}$. (E) Quantification data of $\mathrm{CD}^{+}$cells. The number of $\mathrm{CD} 3^{+}$cells was counted manually using the Image $\mathrm{J} 1.47 \mathrm{v}$ software, and the percentage of $\mathrm{CD}^{+}$cells per DAPI ${ }^{+}$cells was calculated ( $n=6$ mice per group). Mean $\pm \mathrm{SEM}$ were plotted. Statistical significance was determined using ANOVA with Tukey's post hoc test. ${ }^{*} P<0.05$ and ${ }^{* *} P<0.001$ versus WT; ${ }^{\#} P<0.05$ and ${ }^{\# \#} P<0.001$ versus 6 weeks. 
A

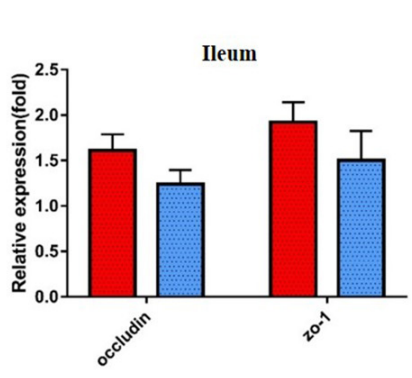

$\mathbf{D}$

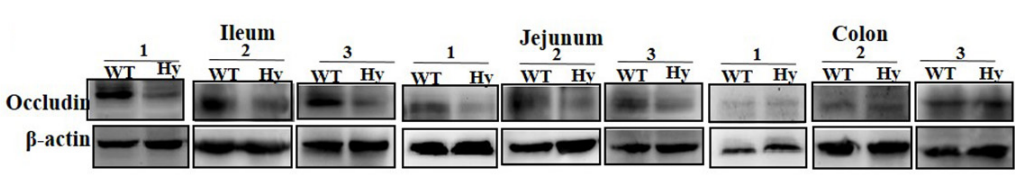

E
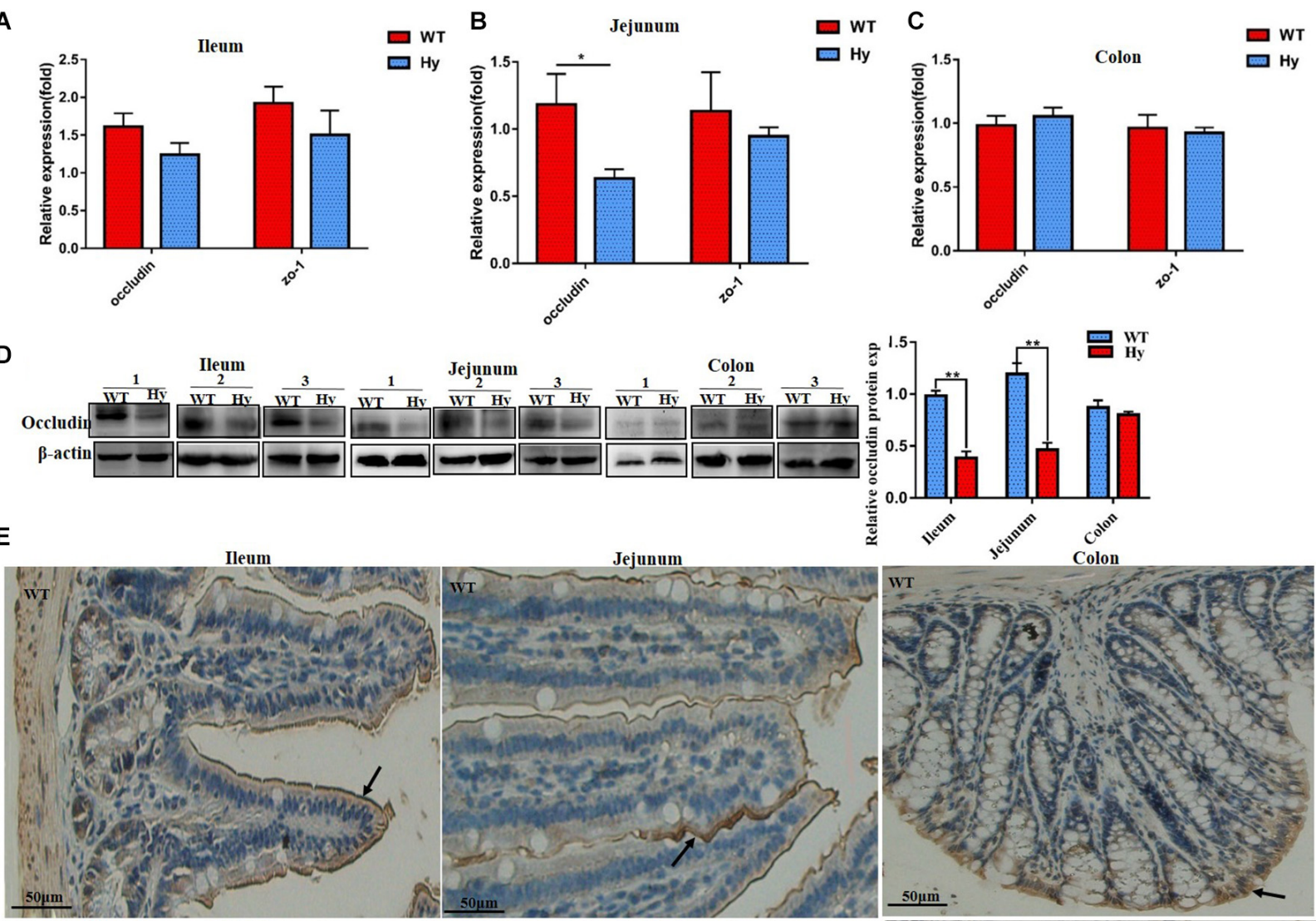
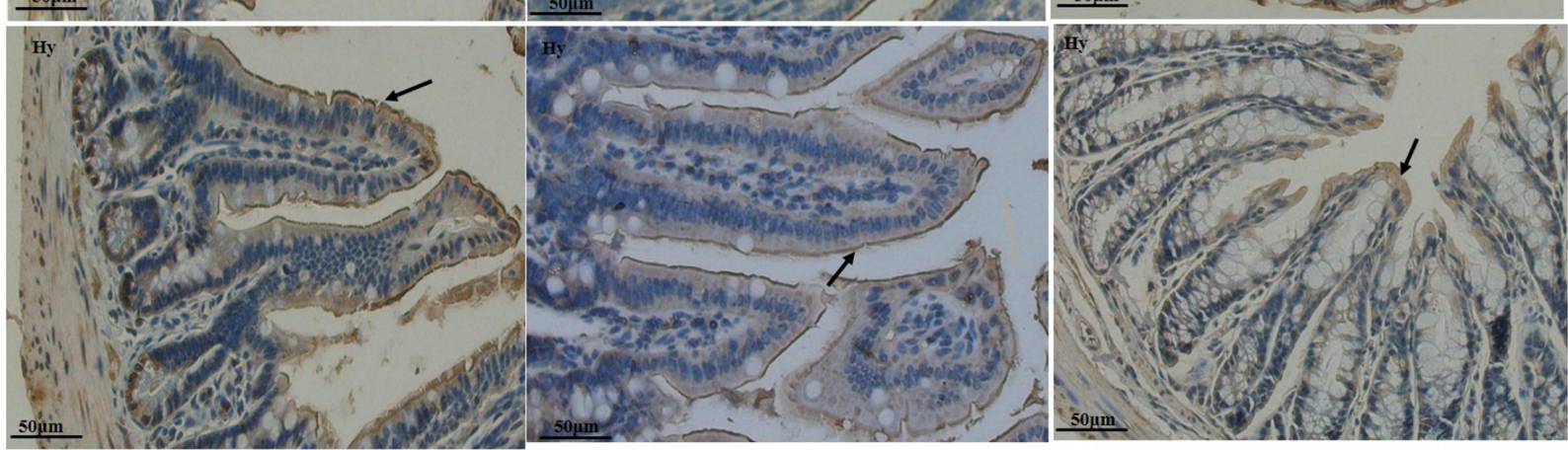

$\mathbf{F}$
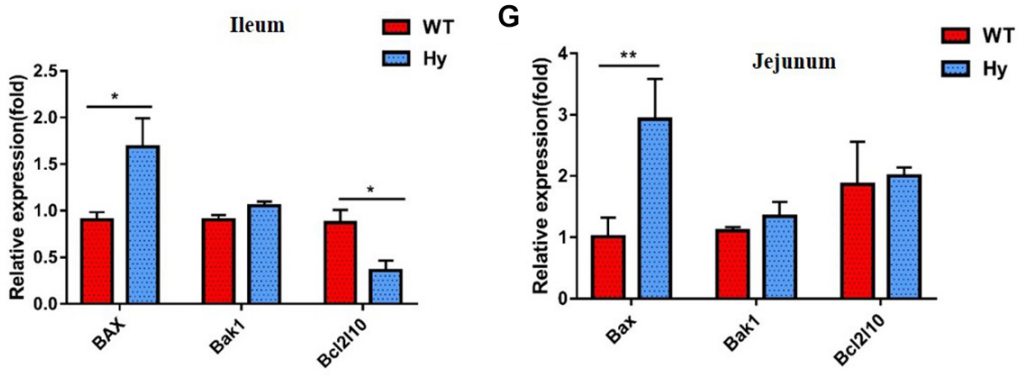

H

$\square$ WT

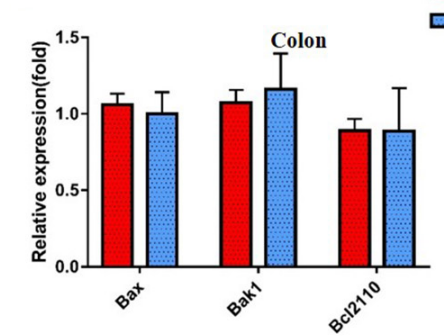

FIGURE $\mathbf{5}$ | Hyperuricemia altered the expression of tight junction proteins. (A-C) Gene expression of occludin and ZO-1 in the ileum (A,B), and colon (C) was determined using Q-PCR. (D) Protein density of occludin from the ileum, jejunum, and colon tissues was determined using Western blot analysis. Data represent three independent experiments. (E) Immunohistochemical staining for claudin-1 (brown, marked with arrows) in the ileum, jejunum, and colon. All photos were taken at $200 \times$, scare bar $=50 \mu \mathrm{m}$. (F-H) Expression of anti-apoptotic protein BCL-B (Bcl2/10) and pro-apoptotic genes Bak1 and Bax in the ileum (F), jejunum (G), and colon $\mathbf{( H )}$ was determined using Q-PCR ( $n=6$ mice per group). Mean \pm SEM were plotted. Statistical significance was determined using the Student unpaired-sample $t$-test $\left({ }^{\star} P<0.05\right.$ and $\left.{ }^{* *} P<0.001\right)$. 


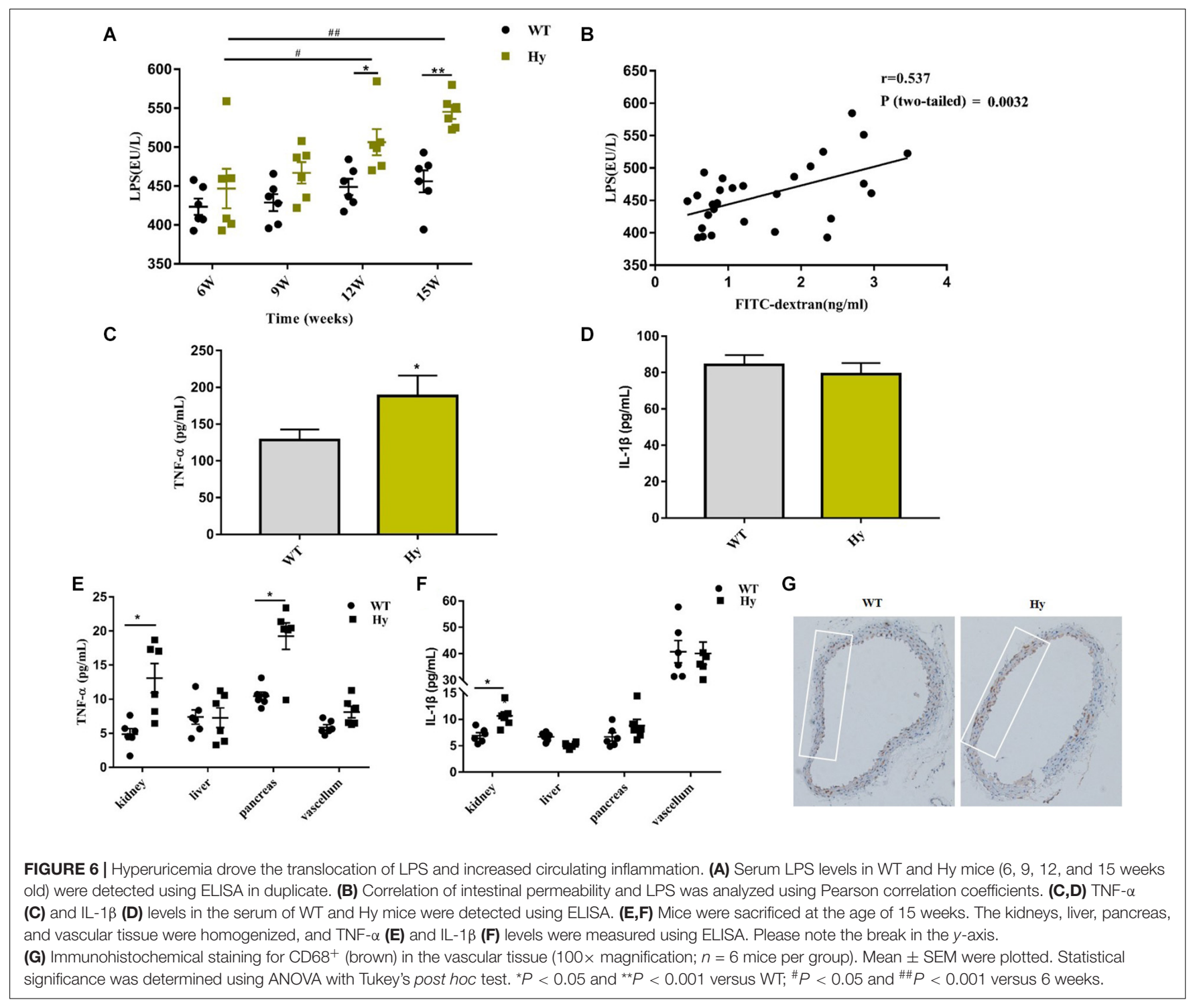

while the expression of the anti-apoptotic gene $B c l 21$ reduced in the ileum. The expression of Bak1 remained unchanged.

\section{Compromised Barrier Was Associated With Increased Systemic Inflammation}

This study further explored whether the compromised barrier could result in the influx of microbial products in the system circulation. Consistently, the circulating levels of LPS were higher in hyperuricemia mice than in WT mice. Notably, the level of LPS in hyperuricemia also increased with age (Figure 6A), which was in tandem with increased intestinal permeability. However, the level of LPS did not increase at different time points in WT mice compared with hyperuricemia mice. A close positive correlation was observed between intestinal permeability and the circulating LPS level (Figure 6B). These findings indicated that a compromised barrier drove the LPS influx in the system circulation.
LPS could trigger a series of pro-inflammatory responses. Therefore, it was hypothesized that high systemic levels of LPS might provoke an overt systemic inflammation. As shown in Figure 6C, the circulating levels of TNF- $\alpha$ increased in hyperuricemic mice. However, the serum IL-1 $\beta$ levels did not increase despite high levels of LPS (Figure 6D). It was further hypothesized that the increased systemic dissemination of microbial products and pathogenic factors as a result of the impaired intestinal barrier, might have a direct effect on multiple organs. The levels of pro-inflammatory cytokines TNF$\alpha$ and IL- $1 \beta$ were detected in various organs. As shown in Figures 6E,F, the concentration of TNF- $\alpha$ was significantly elevated in the kidneys and pancreas, but no change was observed in the liver and vascellum. However, the expression of IL-1 $\beta$ was upregulated only in the kidneys (Figures 6E,F). Furthermore, significant infiltration areas of macrophages (CD68+) were found in the vascellum (Figure 6G). These data displayed a low-grade inflammation in the kidneys, pancreas, and vascellum. 


\section{DISCUSSION}

Accumulating evidence has emphasized the involvement of gut microbiota in hyperuricemia. However, whether the changes in microbiota result in gut pathology is still unknown. Besides, the mechanistic basis for intestinal immunity in hyperuricemia remains poorly understood. This study was novel in examining changes and the mechanism of intestinal immunity in hyperuricemic mice. Hyperuricemic mice suffered from disturbance of the intestinal flora, with an increased abundance of inflammation-associated microbiota. Hyperuricemic mice developed a pro-inflammatory pattern of intestinal immune dysregulation characterized by increased expression of TLR2/4/5, IL- $1 \beta$, and TNF- $\alpha$. Consequently, dysregulated intestinal immunity and gut dysbiosis coincided to disrupt the intestinal barrier and promote the influx of microbial influx in the system circulation. The study was novel in yielding a report substantiating the changes in intestinal immunity in hyperuricemic mice and suggesting target treatments from a new perspective.

The intestinal tract is home to thousands of microbial communities in the body. Changes in microbiota may cause diseases. Many studies have linked gout to gut microbial dysbiosis. In patients with gout, microbiota with the xanthine dehydrogenase gene are enriched whereas microbiota with the allantoinase gene, which degraded uric acid to urea, are depleted (Guo et al., 2016). Thus, gut microbiota might be a novel treatment target for gout. Consistent with the available data, microbiota dysbiosis occurred in hyperuricemic mice. The abundance of health-promoting probiotics or microbiota with the functional capacity of producing butyrate (such as Clostridium and Lactobacillus) (Koji et al., 2014) decreased in hyperuricemic mice in the present study. However, the prevalence of microbiota exacerbated or implicated in intestinal inflammation, such as Alistipes and Parabacteroides, increased (Bassett et al., 2015; Walujkar et al., 2018). Furthermore, the microbiota positively correlated with uric acid and was also highly correlated with intestinal inflammation. Evidence shows that microbiota affected intestinal immunity by changing the levels of anti-inflammatory species, decreasing bacterial richness, changing microbe-microbe interactions, or producing bacterial metabolites (Anne et al., 2012; Emmanuelle et al., 2013). However, previous reports highlighted only the importance of both the composition and function of microbiota but the effects of these changes on intestinal immunity remain unclear.

This study examined intestinal immune dysregulation in hyperuricemic mice, demonstrating the abnormal expression of TLR, infiltration of lymphocytes, and increased levels of pro-inflammatory cytokines in different parts of the bowel. Disturbance in the intestinal flora and increased inflammation in the intestine have also been reported in other mouse models of obesity and diabetes (Brown et al., 2013). Increased levels of pro-inflammatory cytokines, such as TNF- $\alpha$, IL-1 $\beta$, IL-6, and IL-12, were observed in the intestinal tissue of mouse models with obesity (Maynard et al., 2012), which was consistent with the present findings. TNF- $\alpha$ levels increased in both the intestinal tissue and serum of hyperuricemic mice. Winer et al. also demonstrated the important role of TNF$\alpha$ in both HFD- and inflammatory bowel disease-induced barrier dysfunction. Gut immune cells have been shown with the ability to traffic lymphoid organs, such as the spleen (Morton et al., 2014). Thus, the elevated levels of circulating TNF- $\alpha$ in hyperuricemic might may also be derived from the bowel lumen due to the compromised intestinal barrier. TNF knockout mice showed protection against age-associated systemic inflammation (Thevaranjan et al., 2017). However, whether an equivalent effect existed in hyperuricemia as in age-associated systemic inflammation was unclear. Furthermore, among several TLRs, the TLR2 mRNA level significantly increased in every part of the intestine, especially in the jejunum. Both protein and mRNA levels increased in the jejunum. TLR2 interacted with ligands, including bacterial lipopeptides, lipoteichoic acid, and yeast zymosan, to increase apical tightening through the activation of PKC- $\alpha$ and PKC$\delta$ signaling pathways. However, under pathologic conditions, it promoted intestinal inflammation (Cario et al., 2004; Schultz et al., 2007). The overexpression of TLR2 in the jejunum might predict an aggravating intestinal inflammation, which needs further investigation.

The intestinal barrier provides a physical barrier against the excessive entry of luminal microbiota or damaging agents into the systemic circulation (Farhadi et al., 2010). The balanced interaction between microbiota and intestinal immunity is important to maintain a healthy mucosal barrier function. Once the intestinal epithelial barrier is breached, multiple organs are exposed to pathogenic microbiota and products. Evidence shows intestinal barrier dysfunction is a distinctive feature of metabolic diseases (Ekihiro and Bernd, 2012; Rera et al., 2012; Kristoff et al., 2014). Hyperglycemia drives intestinal barrier permeability in mouse models of obesity and diabetes, leading to the systemic influx of microbial products and enhanced systemic infection and inflammation (Thaiss et al., 2018). Alcohol-induced tissue damage and organ dysfunction were also accompanied by gut leakiness (Patel et al., 2015). Hyperuricemia is consistently characterized by increased intestinal permeability. Notably, intestinal permeability increased with age and levels of circulating LPS in hyperuricemic mice. Clinically, elderly individuals have a high risk of suffering from hyperuricemia. However, the related mechanism remains unclear. Thevaranjan reported that intestinal permeability increased with age, leading to the entry of microbial products into the bloodstream and triggering systemic inflammation (Thevaranjan et al., 2018). These data were consistent with the findings of the present study. The study also reported a positive correlation of levels of uric acid with intestinal permeability. Increased inflammation in the intestine led to the dysfunction of the intestinal barrier and disturbed crosstalk between the host and microbiota, further affecting the transport of uric acid and aggravating the progression of hyperuricemia. Thus, increased intestinal permeability with age might be the pivotal risk factor for hyperuricemia.

Recently, growing evidence has indicated that a compromised intestinal barrier preceded systemic inflammation (Shmagel et al., 2016; Andersen et al., 2017; Rizzetto et al., 2018). Similarly, 
increased levels of circulating LPS and TNF- $\alpha$ were observed in hyperuricemic mice, indicating systemic inflammation. Multiple organs also had a state of low-grade inflammation. A marked inflammatory response was noted especially in the pancreas and vascellum. Both basic and clinical studies have evidenced hyperuricemia as an independent risk factor for insulin resistance and atherosis (Kim et al., 2018; Sunagawa et al., 2018), but they examined the mechanism only in terms of direct inflammation and increase in the uric acid level. It appeared as if the elevated serum LPS was the consequence of increased intestinal permeability in patients with insulin resistance and vascular injury. LPS is the activator of pro-inflammatory cytokines, such as TNF- $\alpha$, IL- $1 \beta$, and IL-6, contributing to the development of insulin resistance (Olefsky and Glass, 2010). Estes et al. (2010) demonstrated that reducing the levels of circulating LPS attenuated immune dysfunction and systemic inflammation. The present study only evaluated the level of LPS in the serum, however, it is possible that LPS also entered the organs through systemic circulation in the form of chylomicrons (Yuehui et al., 2009). No changes were found in glucose levels. It was presumed that LPS was a risk factor for diabetes, but not a directly influencing factor. The levels of HDL and LDL increased in hyperuricemic mice, which contradicted previous findings. HDL has been considered to be a so-called "good cholesterol" because it reduces the risk of clogged arteries and atherosclerosis. However, a recent study showed that extremely high levels of HDL might be associated with an increased risk of heart attack and death (Madsen et al., 2017). The present study obtained a similar result, but the mechanism was unknown. This finding might be ascribed to hyperuricemiainduced dyslipidemia. However, further studies are needed to elucidate the mechanism.

Collectively, this study was novel in clarifying the change and mechanism of intestinal immunity in hyperuricemia and demonstrating the strong correlation of hyperuricemia with gut barrier dysfunction. Furthermore, the dysfunction of the intestinal barrier and imbalance in host-microbiome crosstalk was vital in aggravating hyperuricemia and the associated metabolic syndrome. This study suggests novel therapeutic targets against hyperuricemia from a new perspective.

\section{REFERENCES}

Abeles, A. M. (2015). Hyperuricemia, gout, and cardiovascular disease: an update. Curr. Rheumatol. Rep. 17, 1-5. doi: 10.1007/s11926-0150495-2

Andersen, K., Kesper, M. S., Marschner, J. A., Konrad, L., Ryu, M., Kumar, V. S., et al. (2017). Intestinal dysbiosis, barrier dysfunction, and bacterial translocation account for CKD-related systemic inflammation. J. Am. Soc. Nephrol. 28, 76-83. doi: 10.1681/asn.2015111285

Anne, V., Els, V. N., Frits, H., Jarkko, S. R., Kootte, R. S., Bartelsman, J. F. W. M., et al. (2012). Transfer of intestinal microbiota from lean donors increases insulin sensitivity in individuals with metabolic syndrome. Gastroenterology 143, 913-916. doi: 10.1053/j.gastro.2012.06.031

Atsushi, H., Takeo, N., Takuya, F., and Ikumi, T. (2012). Extra-renal elimination of uric acid via intestinal efflux transporter BCRP/ABCG2. PLoS One 7:e30456. doi: 10.1371/journal.pone.0030456

\section{DATA AVAILABILITY STATEMENT}

The RNA sequencing data have been deposited in GEO public repositories accession GSE143342. 16s RNA date was deposited in BioProject, ID: PRJNA600173.

\section{ETHICS STATEMENT}

The studies involving human participants were reviewed and approved by the ethical committee of the Affiliated Hospital of Qingdao University. The patients/participants provided their written informed consent to participate in this study. The animal study was reviewed and approved by Animal Research Ethics Committee of the Affiliated Hospital of Qingdao University.

\section{AUTHOR CONTRIBUTIONS}

SX designed the study and revised the manuscript. QL and DX performed the experiments and wrote the manuscript. XY contributed significantly to the analysis. XL, WY, and PZ helped with critical discussions. XZ and GY revised the manuscript. All the authors contributed to the article and approved the submitted version.

\section{FUNDING}

This study was funded by the National Natural Science Foundation of China (81671625, 81100554, and 81901575), Shandong Province Natural Science Fund Project (ZR2018PH010 and ZR2014HM015), the Young and Middle-Aged Scientists Research Awards Fund of Shandong Province (BS2012YY003), the Scientific and Technical Development Project of Department of Health of Shandong Province (2011QZ007 and 2016WS0259), a project run by the Shandong Province Higher Educational Science and Technology Program (J14LK11), and the Scientific and Technical Development Project of Qingdao [12-14-20-jc, 2012-1-3-2-(1)-nsh, 2013-13-008-YY, 2014-1-72, and 17-3-3-15-nsh].

Bardin, T., and Richette, P. (2017). Impact of comorbidities on gout and hyperuricaemia: an update on prevalence and treatment options. BMC Med. 15:123. doi: 10.1186/s12916-017-0890-9

Bassett, S. A., Wayne, Y., Barnett, M. P. G., Cookson, A. L., Mcnabb, W. C., and Roy, N. C. (2015). Changes in composition of caecal microbiota associated with increased colon inflammation in interleukin-10 gene-deficient mice inoculated with Enterococcus species. Nutrients 7, 1798-1816. doi: 10.3390/nu7031798

Brown, E. M., Sadarangani, M., and Finlay, B. B. (2013). The role of the immune system in governing host-microbe interactions in the intestine. Nat. Immunol. 14, 205-205. doi: 10.1038/ni0214-205d

Cario, E., Gerken, G., and Podolsky, D. K. (2004). Toll-like receptor 2 enhances ZO-1-associated intestinal epithelial barrier integrity via protein kinase C. Gastroenterology 127, 224-238. doi: 10.1053/j.gastro.2004.04.015

Crane, J. K. (2013). Role of host xanthine oxidase in infection due to enteropathogenic and Shiga-toxigenic Escherichia coli. Gut Microbes 4, 388391. doi: $10.4161 /$ gmic. 25584 
Debosch, B. J., Kluth, O., Fujiwara, H., Schürmann, A., and Moley, K. (2014). Earlyonset metabolic syndrome in mice lacking the intestinal uric acid transporter SLC2A9. Nat. Commun. 5:4642.

Ekihiro, S., and Bernd, S. (2012). Role of innate immunity and the microbiota in liver fibrosis: crosstalk between the liver and gut. J. Physiol. 590, 447-458. doi: 10.1113/jphysiol.2011.219691

Emmanuelle, L. C., Trine, N., Junjie, Q., Edi, P., Falk, H., Gwen, F., et al. (2013). Richness of human gut microbiome correlates with metabolic markers. Nature $500,541-546$.

Estes, J. D., Harris, L. D., Klatt, N. R., Brian, T., Stefania, P., Mirko, P., et al. (2010). Damaged intestinal epithelial integrity linked to microbial translocation in pathogenic simian immunodeficiency virus infections. PLoS Pathog. 6:e1001052. doi: 10.1371/journal.ppat.1001052

Farhadi, A., Banan, A., Fields, J., and Keshavarzian, A. (2010). Intestinal barrier: an interface between health and disease. J. Gastroenterol. Hepatol. 18, 479-497. doi: 10.1046/j.1440-1746.2003.03032.x

Guo, Z., Zhang, J., Wang, Z., Ang, K. Y., Huang, S., Hou, Q., et al. (2016). Intestinal microbiota distinguish gout patients from healthy humans. Sci. Rep. 6:20602.

Hosomi, A., Nakanishi, T., Fujita, T., and Tamai, I. (2012). Extra-renal elimination of uric acid via intestinal efflux transporter BCRP/ABCG2. PLoS One 7: e30456.

John, K. C., Tonniele, M. N., Jacqueline, E. B., and Edgar, C. B. (2013). Role of host xanthine oxidase in infection due to enteropathogenic and Shiga-toxigenic Escherichia coli. Gut Microbes 4, 388-391.

Johnson, R. J., Takahiko, N. L., Gabriela, S. L., Mohamed, S., Shikha, S., Myphuong, L., et al. (2013). Sugar, uric acid, and the etiology of diabetes and obesity. Diabetes 62, 3307-3315. doi: 10.2337/db12-1814

Kim, S. C., Carli, M. F. D., Garg, R. K., Vanni, K., Wang, P., Wohlfahrt, A., et al. (2018). Asymptomatic hyperuricemia and coronary flow reserve in patients with metabolic syndrome. BMC Rheumatol. 2:17. doi: 10.1186/s41927-018$0027-6$

Koji, A., Takeshi, T., Kenshiro, O., Wataru, S., Yuji, N., Hiroyoshi, N., et al. (2014). Treg induction by a rationally selected mixture of Clostridia strains from the human microbiota. Nature 500, 232-236. doi: 10.1038/nature12331

Kristoff, J., Haret-Richter, G., Ma, D., Ribeiro, R. M., Xu, C., Cornell, E., et al. (2014). Early microbial translocation blockade reduces SIV-mediated inflammation and viral replication. J. Clin. Invest. 124, 2802-2806. doi: 10.1172/ jci75090

Lu, J., Hou, X., Yuan, X., Cui, L., Liu, Z., Li, X., et al. (2018). Knockout of the urate oxidase gene provides a stable mouse model of hyperuricemia associated with metabolic disorders. Kidney Int. 93, 69-80. doi: 10.1016/j.kint.2017.04.031

Madsen, C. M., Varbo, A., and Nordestgaard, B. G. (2017). Extreme high highdensity lipoprotein cholesterol is paradoxically associated with high mortality in men and women: two prospective cohort studies. Eur. Heart J. 38, 2478-2486. doi: 10.1093/eurhearti/ehx163

Maynard, C. L., Elson, C. O., Hatton, R. D., and Weaver, C. T. (2012). Reciprocal interactions of the intestinal microbiota and immune system. Nature 489, 231-241. doi: 10.1038/nature11551

Morton, A. M., Sefik, E., Upadhyay, R., Weissleder, R., Benoist, C., and Mathis, D. (2014). Endoscopic photoconversion reveals unexpectedly broad leukocyte trafficking to and from the gut. Proc. Natl. Acad. Sci. U.S.A. 111, 6696-6701. doi: 10.1073/pnas.1405634111

Olefsky, J. M., and Glass, C. K. (2010). Macrophages, inflammation, and insulin resistance. Annu. Rev. Physiol. 72, 219-246. doi: 10.1146/annurev-physiol021909-135846

Patel, S., Behara, R., Swanson, G. R., Forsyth, C. B., Voigt, R. M., and Keshavarzian, A. (2015). Alcohol and the intestine. Biomolecules 5, 2573-2588.

Rera, M., Clark, R. I., and Walker, D. W. (2012). Intestinal barrier dysfunction links metabolic and inflammatory markers of aging to death in Drosophila. Proc. Natl. Acad. Sci. U.S.A. 109, 21528-21533. doi: 10.1073/pnas.1215849110
Rizzetto, L., Fava, F., Tuohy, K. M., and Selmi, C. (2018). Connecting the immune system, systemic chronic inflammation and the gut microbiome: the role of sex. J. Autoimmun. 92, 12-34. doi: 10.1016/j.jaut.2018.05.008

Schultz, A. L. M., Bonnard, A., Barreau, F., Aigrain, Y., Pierre-Louis, C., Berrebi, D., et al. (2007). Expression of TLR-2, TLR-4, NOD2 and pNF-kB in a neonatal rat model of necrotizing Enterocolitis. PLoS One 2:e1102. doi: 10.1371/journal. pone. 0001102

Shao, T., Shao, L., Li, H., Xie, Z., He, Z., and Wen, C. (2017). Combined signature of the fecal microbiome and metabolome in patients with gout. Front. Microbiol. 8:268. doi: $10.3389 /$ fmicb. 2017.00268

Shmagel, N. G., Shmagel, K. V., Korolevskaya, L. B., Saidakova, E. V., and Chereshnev, V. A. (2016). [Systemic inflammation and compromised intestinal barrier during successful treatment of HIV infection]. Klin. Med. 94, $47-51$.

Stearns, J. C., Davidson, C. J., Mckeon, S., Whelan, F. J., Fontes, M. E., Schryvers, A. B., et al. (2015). Culture and molecular-based profiles show shifts in bacterial communities of the upper respiratory tract that occur with age. ISME J. 9, 1246-1259. doi: 10.1038/ismej.2014.250

Sunagawa, S., Shirakura, T., Hokama, N., Kozuka, C., Yonamine, M., Namba, T., et al. (2018). Activity of xanthine oxidase in plasma correlates with indices of insulin resistance and liver dysfunction in Japanese patients with type 2 diabetes mellitus and metabolic syndrome: a pilot exploratory study. J. Diabetes Investig. 10, 94-103. doi: $10.1111 /$ jdi.12870

Thaiss, C. A., Levy, M., Grosheva, I., Zheng, D., Soffer, E., Blacher, E., et al. (2018). Hyperglycemia drives intestinal barrier dysfunction and risk for enteric infection. Science 359, 1376-1383. doi: 10.1126/science.aar3318

Thevaranjan, N., Puchta, A., Schulz, C., Naidoo, A., Szamosi, J., Verschoor, C., et al. (2018). Age-associated microbial dysbiosis promotes intestinal permeability, systemic inflammation, and macrophage dysfunction. Cell Host Microbe 23:570. doi: 10.1016/j.chom.2018.03.006

Thevaranjan, N., Puchta, A., Schulz, C., Naidoo, A., Szamosi, J. C., Verschoor, C. P., et al. (2017). Age-associated microbial dysbiosis promotes intestinal permeability, systemic inflammation, and macrophage dysfunction. Cell Host Microbe 21, 455.e4-466.e4.

Walujkar, S. A., Kumbhare, S. V., Marathe, N. P., Patangia, D. V., Lawate, P. S., Bharadwaj, R. S., et al. (2018). Molecular profiling of mucosal tissue associated microbiota in patients manifesting acute exacerbations and remission stage of ulcerative colitis. World J. Microbiol. Biotechnol. 34:76.

Winer, D. A., Luck, H., Tsai, S., and Winer, S. (2016). The intestinal immune system in obesity and insulin resistance. Cell Metab. 23, 413-426. doi: 10.1016/j.cmet. 2016.01.003

Ye, Y. (2011). Identification and quantification of abundant species from pyrosequences of $16 \mathrm{~S}$ rRNA by consensus alignment. IEEE Int. Conf. Bioinform. Biomed. 2010, 153-157.

Yuehui, W., Sarbani, G., Martin, W., Willem, D. V., Jerold, W., and Erik, E. (2009). Chylomicrons promote intestinal absorption and systemic dissemination of dietary antigen (ovalbumin) in mice. J. Lipid Res. 4:e8442. doi: 10.1371/journal. pone. 0008442

Conflict of Interest: The authors declare that the research was conducted in the absence of any commercial or financial relationships that could be construed as a potential conflict of interest.

Copyright (C) 2020 Lv, Xu, Zhang, Yang, Zhao, Cui, Liu, Yang, Yang and Xing. This is an open-access article distributed under the terms of the Creative Commons Attribution License (CC BY). The use, distribution or reproduction in other forums is permitted, provided the original author(s) and the copyright owner(s) are credited and that the original publication in this journal is cited, in accordance with accepted academic practice. No use, distribution or reproduction is permitted which does not comply with these terms. 